\title{
The Prevalence of Functional Disability and Associated Factors among Older People Attending Primary Health-care Centers in Riyadh City
}

\author{
Abdullah Alhalafi ${ }^{1 *}$ (D), Maysoon Al-Amoud ${ }^{2}$, Reema Aldahman $^{3}$, Eman Abd-Ellatif $^{4}$, Doaa Omar $^{5}$ \\ ${ }^{1}$ Department of Community Medicine, College of Medicine, University of Bisha, Bisha, Saudi Arabia; ${ }^{2}$ Older People Health Care \\ Program, General Directorate of Health Programs and Chronic Diseases, Saudi Ministry of Health, Member of the Board of \\ Directors of the Saudi Society of Geriatric Medicine, Riyadh, Saudi Arabia; ${ }^{3}$ General Directorate of Marketing and Awareness, \\ Ministry of Health, Riyadh, Saudi Arabia; ${ }^{4}$ Department of Public Health and Community Medicine, Faculty of Medicine, \\ Mansoura University, Mansoura, Egypt; ${ }^{5}$ Department of Community, Environmental and Occupational Medicine, Faculty of \\ Medicine, Benha University, Benha, Egypt
}

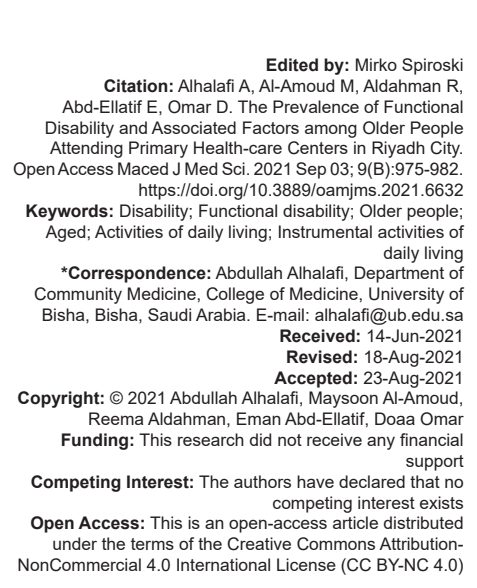

Introduction

Aging is a naturally occurring universal process of all human beings. It includes several changes in an individual's psychological, physical, and healthrelated capabilities [1]. In 2017, the estimated number of people aged 60 years and older globally was 962 million, approximately $13 \%$ of the world population. Furthermore, data show that the number of people aged 60 years and older is growing at a rate of approximately $3 \%$ (in-text citation). Projections predict that the number of older persons in the world by 2030 will be 1.4 billion, 2.1 billion by 2050, and could rise to 3.1 billion by 2100 [2]. These trends are expected to occur among the Saudi population, as the percent of the older people population aged 60 and older in the country is projected to increase by $18.4 \%$ in 2035 [3]. There are several factors that could be linked to the estimated growth in the Saudi subpopulation. For example, reports indicate that from 1980 to 2000 , the Saudi population experienced an expansion due to national development advancements, high birth rates, and improvements in maternal and child health [4].

Medical researchers and policy-makers have concerns about the aging and increased longevity projections. More people reaching older years in life will more likely result in a higher prevalence of disability [5]. Disability is defined as difficulty or dependency in carrying out activities essential to independent living, such tasks needed for self-care and living independently in a home, and other activities important to one's quality of life [5]. The World Health Organization describes three dimensions of disability: (a) Impairment of body function or structure such as impairments of vision or hearing, dementia, or loss of limbs, (b) activity limitation such as the difficulty of walking, problem-solving, and self-care, and (c) participation restrictions in the community, social, and civil life [6]. 
Disability is a significant social and economic problem in Saudi Arabia. For example, in 2016, the prevalence rate of any disability among Saudi citizens was $3.3 \%$, and the rate of disability among those 60 years and older was $11 \%$ [7]. A more recent report indicates that the population percentage in Saudi Arabia with functional disabilities is estimated at $3.73 \%$. However, according to the national demographic survey, the prevalence of disability is nearly $0.8 \%$ of the total Saudi population, approximately 135,000 people. The statistical difference evident in these data reports stems from the conflicting definitions of disability used during the reporting procedures [8].

One reason why a universal definition of disability is difficult to implement could be because the determinants of disability are diverse and vary across different settings. Research on the disability of older persons has identified modifiable risk factors such as geriatric diseases, impairments, functional limitations, unhealthy behaviors, social and environmental obstacles, as well as non-modifiable risk factors including age, gender, and genetics [9]. A disability may lead to extra expenditures for individuals and households. These expenses may relate to general needs (e.g. health care and food), as well as to disability-specific items (e.g. assistive devices, rehabilitation fees, care assistant, and house adaptation) [10].

Limited research has been conducted on the prevalence of functional disability among older persons in the Kingdom of Saudi Arabia (KSA). Most of the research efforts on disability among the Saudi population have focused on disabled children [8].

The aim of the current study, therefore, is to examine the prevalence of functional disability in activities of daily living (ADL), instrumental activities of daily living (IADL), and associated risk factors among older people attending primary health-care centers (PHCCs) in Riyadh City, Saudi Arabia.

\section{Methods}

\section{Study design and participants}

A descriptive cross-sectional study was conducted between December 2019 and May 2020. Participants included Saudi older people $\geq 60$ years who attended in PHCCs in Riyadh city during data collection and agreed to participate in the study. Sample exclusion criteria included individuals that were $<60$ years of age, non-Saudi, had no file in PHCCs in Riyadh City, refused to participate in the study, anyone who was unable to give consent, and those unable to understand and answer the questions. The sample size was calculated using the formula of calculation of the cross-sectional study sample size [11]. The investigators assumed the prevalence rate of disability among Saudi citizens those 60 years and older was $11 \%(7)$, at a 95\% confidence level $(\mathrm{Cl})$ and $3 \%$ margin of error. The total estimated sample size was $n=504$.

\section{Study settings}

The capital of Saudi Arabia, Riyadh, is in the center of the KSA with an occupation of $1800 \mathrm{~km}^{2}$ [12]. According to the United Nations estimation, the population of Riyadh was $6,907,000$ people in 2018 [13]. The city is divided into five geographical sectors: Western, Southern, Middle, Northern, and Eastern. The PHCCs are an important issue across all five sectors. A total of 135 PHCCs are sponsored by the Ministry of Health. For this study, the sample included 25 PHCCs that implemented older people healthcare programs distributed over all five geographical regions. The investigators consecutively selected the first 20 patients from each center during the selected interview days.

\section{Data collection and variables definition}

Data were collected using a questionnaire designed by the researchers. The questionnaire was translated forward to Arabic and backward to English by a professional translator. The questionnaire was selfadministered with the help of an interviewer. When the participant was unable to complete the questionnaire on their own, a caregiver aided in the process. A pilot study was undertaken using the Arabic version of the questionnaire. Nine participants were recruited (clarity, time consumed, and different responses). Their results were not included in the study. The questionnaire was divided into two main categories: (a) Sociodemographic characteristics and health status, and (b) basic ADL and IADL.

\section{Sociodemographic characteristics and health} status

The general section of the questionnaire collected data on participant demographics including age, sex, education, employment, marital status, and the number of persons living with him/her. Furthermore, data on participant health status were also collected by the questionnaire. Participants provided information on the following topics: Having a caregiver, type of caregiver, smoking, diet, exercise, body mass index (BMI), medical history of hypertension, diabetes mellitus, dyslipidemia, rheumatoid arthritis, stroke, heart disease, cancer, history of falls and fractures in the past 12 months, history of emergency department visits, homecare, and hospitalization in the past 3 months. 


\section{Basic ADL and IADL}

The Katz index was used to characterize basic ADLs (i.e. bathing, dressing, eating, toileting, and making bed-wheelchair transfers), whereas the Lawton and Brody scale was used to characterized IADLs (i.e. using the phone, going to distant places, shopping, preparing meals, doing household chores, managing money, taking drugs, and handling small objects). A score of 0 (when no performing the correspondent activity) or 1 (when performing the correspondent activity) was attributed to each item. If none of the ADL/IADL activities were impaired, the individual was classified as "independent;" if one or two activities were impaired, he or she was classified as "moderately dependent;" and finally, "severely dependent" refers to older people who had three or more activities impaired [14], [15]. The reliability of the Katz index has been well documented. Furthermore, it has an adequate and acceptable validity in assessing basic ADL [16], [17], [18]. Furthermore, the Lawton and Brody scale has been previously used to test for IADL screening [19], [20].

\section{Data management and analysis}

Data were analyzed using the Statistical Package for the Social Sciences software version 22.0. Descriptive analysis was conducted using frequencies, percentages, mean, and standard deviation to describe the sociodemographic characteristics, health status, Katz index, and Lawton and Brody scale. The prevalence of ADL and IADL disabilities was stratified by sociodemographic and health status factors, and the Chi-square test $\left(\chi^{2}\right)$ was used to measure the association between functional disabilities with independent variables. Third, a binary logistic regression model was performed to identify different factors predicting ADL and IADL disabilities. Odds ratio and $95 \% \mathrm{Cl}$ were obtained from logistic regression models. $p<0.05$ was considered statistically significant (two-sided tests).

\section{Ethical consideration}

Institution review board approval was obtained from King Fahad Medical City, Ministry of Health. Informed written consents in Arabic were obtained from all participants. The study objectives were clarified to them. To assure anonymity, participant's names and file numbers were not collected.

\section{Results}

\section{Sociodemographic characteristics and health status}

Among the 504 participants, 280 (55.6\%) were female and $224(44.4 \%)$ were male. Their mean age was $68.6 \pm 7.5$ years. The majority of them were illiterate 221 (43.8\%). Only $34(6.7 \%)$ were employed and many did not work $283(56.2 \%)$ or were retired $187(37.1 \%)$. Nearly two-thirds of subjects were married 350 (69.4\%), while one-third were either single, divorced, or widowed. More than half of the participants were living with husbands/wives with children $314(62.3 \%)$, and $127(25.2 \%)$ were living with relatives and their children. The median number of people who lived with older people was $5 \pm 3$ persons. Many of the participants had a caregiver (308 out of $504 ; 61.1 \%)$. Approximately half of the participants had a family member as their caregiver (258 out of 504; $51.2 \%)$, and only 37 participants $(7.3 \%)$ were overseen by a paid caregiver. Near four-fifths of the participants (409 out of $504 ; 81.2 \%$ ) did not smoke, 65 (12.9\%) were ex-smokers, and $30(6 \%)$ were active smokers. The majority of the subjects, 467 out of 504 (92.7\%), did not follow diets, and 346 (68.7\%) did not perform a regular exercise routine. The mean BMI of subjects was $29.8 \pm 5.3 \mathrm{~kg} / \mathrm{m}^{2}$.

This study examined the prevalence of the most common chronic disease among the sampled participants. Most of subjects were diagnosed with hypertension $351(69.6 \%)$ followed by diabetes mellitus $342(67.9 \%)$. Half of subjects (253 out of $504 ; 50.2 \%$ ) had dyslipidemia. Furthermore, the following diseases were respectively noted: Rheumatoid arthritis (96; $19 \%)$, heart-disease $(58 ; 11.5 \%)$, stroke $(13 ; 2.6 \%)$, and cancer $(6 ; 1.2 \%)$.

Out of the total subjects, $60(11.9 \%)$ reported a history of falls during the past year, and $8(1.6 \%)$ had a fracture during the same period. There were 75 participants $(14.9 \%)$ that visited emergency, $22(4.4 \%)$ needed homecare, and 42 (8.3\%) were hospitalized. Findings on sociodemographic characteristics and health status are displayed in Tables 1 and 2 .

\section{$A D L$ disability}

Most of the study subjects who attended PHCCs in Riyadh city were independents $75.4 \%$. Oppositely, the overall prevalence of ADL disability among the participants was $24.6 \%$, as presented in Table 3. Furthermore, the prevalence of ADL moderate disability was $18.5 \%$, while severe disability was $6.2 \%$. In particular, the most affected function was transferring $(13.5 \%)$, followed by continence $(12.3 \%)$, dressing $(8.1 \%)$, bathing $(7.1 \%)$, toileting $(4.6 \%)$, and feeding $(3.6 \%)$.

The univariate analysis of sociodemographic data and health status with ADL, as shown in Table 4, showed that the subjects aged 68 years and older were more likely to had disabilities than younger ones $(p=0.001)$, illiterate than educated $(p=0.026)$, unmarried than married $(p=0.017)$, who had a caregiver than have not $(p=0.004)$, who had a paid caregiver versus a family member $(p=0.008)$, ex-smoker $(p=$ 
Table 1: Sociodemographic characteristics of participants

\begin{tabular}{llll}
\hline Factor & Level & $\mathrm{n}$ & $\%$ \\
\hline Age & Mean \pm SD & $68.61 \pm 7.545$ \\
& <68years & 268 & 53.2 \\
Sex & $\geq 68$ years & 236 & 46.8 \\
& Male & 224 & 44.4 \\
Education & Female & 280 & 55.6 \\
& Illiterate & 221 & 43.8 \\
& Read and write & 88 & 17.5 \\
& Primary & 54 & 10.7 \\
& Intermediate & 36 & 7.1 \\
& Secondary & 42 & 8.3 \\
Employment & University & 56 & 11.1 \\
& Postgraduate & 7 & 1.4 \\
Marital status & Employed & 34 & 6.7 \\
& Not work & 283 & 56.2 \\
& Retired & 187 & 37.1 \\
Living with & Single & 3 & 0.6 \\
& Married & 350 & 69.4 \\
& Divorced & 21 & 4.2 \\
& Widowed & 130 & 25.8 \\
Number of persons living with him/her & Husband/wife & 42 & 8.3 \\
Having a caregiver & Husband/wife with children & 314 & 62.3 \\
& Relatives & 127 & 25.2 \\
Type of caregiver & Alone & 18 & 3.6 \\
& Others & 3 & 0.6 \\
& <5 & 243 & 48.2 \\
& No & 261 & 51.8 \\
& Yes & 196 & 38.9 \\
& Family member & 308 & 61.1 \\
& Paid caregiver & 258 & 51.2 \\
& & 37 & 7.3 \\
\hline
\end{tabular}

0.026 ), and who were inactive than who did regular exercise $(p=0.001)$. Moreover, the disability associated with hypertension $(p=0.040)$, dyslipidemia $(p=0.001)$, rheumatoid arthritis $(p<0.001)$, stroke $(p=0.005)$, history of fracture $(p=0.025)$, history of falls in the past 12 months, emergency visits, homecare, and hospitalization in the past 3 months $(p<0.001)$ for all.

Table 2: Lifestyle and health characteristics of participants

\begin{tabular}{llll}
\hline Factor & Level & $\mathrm{n}$ & $\%$ \\
\hline Smoking & No & 409 & 81.2 \\
& Yes & 30 & 6.0 \\
& Ex-smoker & 65 & 12.9 \\
Diet & No & 467 & 92.7 \\
& Yes & 37 & 7.3 \\
Exercise & No & 346 & 68.7 \\
& Yes & 158 & 31.3 \\
Body mass index $\left(\mathrm{kg} / \mathrm{m}^{2}\right)$ & $<30$ & 282 & 56.0 \\
& $\geq 30$ & 222 & 44.0 \\
Hypertension & No & 153 & 30.4 \\
& Yes & 351 & 69.6 \\
Diabetes mellitus & No & 162 & 32.1 \\
& Yes & 342 & 67.9 \\
Dyslipidemia & No & 251 & 49.8 \\
& Yes & 253 & 50.2 \\
Rheumatoid arthritis & No & 408 & 81.0 \\
& Yes & 96 & 19.0 \\
Stroke & No & 491 & 97.4 \\
& Yes & 13 & 2.6 \\
Heart disease & No & 446 & 88.5 \\
Cancer & Yes & 58 & 11.5 \\
& No & 498 & 98.8 \\
History of falls in the past 12 months & Yes & 6 & 1.2 \\
& No & 444 & 88.1 \\
History of fracture in the past 12 months & Yes & 60 & 11.9 \\
& No & 496 & 98.4 \\
Emergency visits in the past 3 months & Yes & 8 & 1.6 \\
& No & 429 & 85.1 \\
Homecare in the past 3 months & Yes & 75 & 14.9 \\
& No & 482 & 95.6 \\
Hospitalization in the past 3 months & Yes & 22 & 4.4 \\
& No & 462 & 91.7 \\
\hline
\end{tabular}

The logistic regression model showed that ADL disability was significantly associated with smokers

Table 3: Assessment of ADL/IADL disability

\begin{tabular}{llllll}
\hline & \multicolumn{2}{c}{ ADL disability } & & \multicolumn{2}{c}{ IADL disability } \\
\cline { 2 - 3 } & $\mathrm{n}$ & $\%$ & & $\mathrm{n}$ & $\%$ \\
\hline Independent & 380 & 75.4 & & 209 & 41.5 \\
Moderate disability & 93 & 18.5 & & 195 & 38.7 \\
Severe disability & 31 & 6.2 & & 100 & 19.8 \\
\hline ADL: Activities of daily living, IADL: Instrumental activities of daily living. & &
\end{tabular}

Table 4: Factors associated with ADL/IADL disability (univariate analysis)

\begin{tabular}{|c|c|c|c|c|c|c|}
\hline \multirow[t]{2}{*}{ Variables } & \multicolumn{3}{|c|}{ ADL disability } & \multicolumn{3}{|c|}{ IADL disability } \\
\hline & Yes & $\%$ & $\mathrm{p}$ & Yes & $\%$ & $\mathrm{p}$ \\
\hline \multicolumn{7}{|l|}{ Age } \\
\hline$<68$ & 49 & 18.3 & \multirow[t]{2}{*}{$0.001^{*}$} & 132 & 49.3 & \multirow[t]{2}{*}{$0.000^{*}$} \\
\hline$\geq 68$ & 75 & 31.8 & & 163 & 69.1 & \\
\hline Sex & & & & & & \\
\hline Male & 56 & 25 & 0.935 & 92 & 41.1 & $0.000^{*}$ \\
\hline Female & 68 & 24.3 & & 203 & 72.5 & \\
\hline Education & & & & & & \\
\hline Illiterate & 87 & 28.2 & $0.026^{*}$ & 226 & 73.1 & $0.000^{*}$ \\
\hline Literate & 37 & 19 & & 69 & 35.4 & \\
\hline Employment & & & & & & \\
\hline Employed & 7 & 20.6 & 0.306 & 9 & 26.5 & $0.000^{*}$ \\
\hline Not work & 77 & 27.2 & & 212 & 74.9 & \\
\hline Retired & 40 & 32.3 & & 74 & 39.6 & \\
\hline Marital status & & & & & & \\
\hline Unmarried & 49 & 31.8 & $0.017^{*}$ & 115 & 74.7 & $0.000^{*}$ \\
\hline Married & 75 & 21.4 & & 180 & 51.4 & \\
\hline Living with & & & & & & \\
\hline Husband/wife & 80 & 22.5 & 0.108 & 185 & 52.0 & $0.000^{*}$ \\
\hline Others & 44 & 29.7 & & 110 & 74.3 & \\
\hline Number of person & & & & & & \\
\hline$<5$ & 55 & 22.6 & 0.375 & 149 & 61.3 & 0.257 \\
\hline$\geq 5$ & 69 & 26.4 & & 146 & 55.9 & \\
\hline Having a caregive & & & & & & \\
\hline No & 34 & 17.3 & $0.004^{*}$ & 70 & $64.3 \%$ & $0.000^{*}$ \\
\hline Yes & 90 & 29.2 & & 225 & 73.1 & \\
\hline Type of caregiver & & & & & & \\
\hline Family member & 72 & 27.9 & $0.008^{*}$ & 197 & 76.4 & $0.000^{*}$ \\
\hline Paid caregiver & 14 & 37.8 & & 20 & 54.1 & \\
\hline Smoking & & & & & & \\
\hline No & 101 & 24.7 & $0.026^{*}$ & 257 & 62.8 & $0.000^{*}$ \\
\hline Yes & 2 & 6.7 & & 10 & 33.3 & \\
\hline Ex-smoker & 21 & 32.3 & & 28 & 43.1 & \\
\hline Diet & & & & & & \\
\hline No & 118 & 25.3 & 0.302 & 278 & 59.5 & 0.150 \\
\hline Yes & 6 & 16.2 & & 17 & 45.9 & \\
\hline Exercise & & & & & & \\
\hline No & 101 & 29.2 & $0.001^{*}$ & 244 & 70.5 & $0.000^{*}$ \\
\hline Yes & 23 & 14.6 & & 51 & 32.3 & \\
\hline Body mass index & & & & & & \\
\hline$<30$ & 69 & 24.5 & 1.000 & 122 & 43.3 & 0.406 \\
\hline$\geq 30$ & 55 & 24.8 & & 87 & 39.2 & \\
\hline Hypertension & & & & & & \\
\hline No & 28 & 18.3 & $0.040^{*}$ & 76 & 49.7 & $0.010^{*}$ \\
\hline Yes & 96 & 27.4 & & 219 & 62.4 & \\
\hline Diabetes mellitus & & & & & & \\
\hline No & 35 & 21.6 & 0.335 & 86 & 53.1 & 0.107 \\
\hline Yes & 89 & 26 & & 209 & 61.1 & \\
\hline Dyslipidemia & & & & & & \\
\hline No & 45 & 17.9 & $0.001^{*}$ & 144 & 57.4 & 0.662 \\
\hline Yes & 79 & 31.2 & & 151 & 59.7 & \\
\hline Rheumatoid arthri & & & & & & \\
\hline No & 83 & 20.3 & $0.000^{*}$ & 237 & 58.1 & 0.763 \\
\hline Yes & 41 & 42.7 & & 58 & 60.4 & \\
\hline Stroke & & & & & & \\
\hline No & 116 & 23.6 & $0.005^{*}$ & 287 & 58.5 & 1.000 \\
\hline Yes & 8 & 61.5 & & 8 & 61.5 & \\
\hline Heart disease & & & & & & \\
\hline No & 105 & 23.5 & 0.170 & 262 & 58.7 & 0.899 \\
\hline Yes & 19 & 32.8 & & 33 & 56.9 & \\
\hline Cancer & & & & & & \\
\hline No & 123 & 24.7 & 1.000 & 289 & 58 & $0.044^{*}$ \\
\hline Yes & 1 & 16.7 & & 6 & 100 & \\
\hline History of falls in $t$ & & & & & & \\
\hline No & 95 & 21.4 & $0.000^{*}$ & 257 & 57.9 & 0.506 \\
\hline Yes & 29 & 48.3 & & 38 & 63.3 & \\
\hline History of fracture & & & & & & \\
\hline No & 119 & 24 & $0.025^{*}$ & 288 & 58.1 & 0.148 \\
\hline Yes & 5 & 62.5 & & 7 & 87.5 & \\
\hline Emergency visits & & & & & & \\
\hline No & 86 & 20 & $0.000^{*}$ & 242 & 56.4 & $0.029^{*}$ \\
\hline Yes & 38 & 50.7 & & 53 & 70.7 & \\
\hline Homecare in the $p$ & & & & & & \\
\hline No & 109 & 22.6 & $0.000^{*}$ & 275 & 57.1 & $0.003^{*}$ \\
\hline Yes & 15 & 68.2 & & 20 & 90.9 & \\
\hline Hospitalization in & & & & & & \\
\hline No & 102 & 22.1 & $0.000^{*}$ & 271 & 58.7 & 0.978 \\
\hline Yes & 22 & 52.4 & & 24 & 57.1 & \\
\hline
\end{tabular}

and ex-smokers, inactive subjects, comorbidity with dyslipidemia or rheumatoid arthritis, history of falls in the past 12 months, and emergency visits and homecare in the past 3 months. The model showed that the hazard of disability development increased by 2.1 times when older people were already smokers 
compared with non-smoker ( $p=0.019$ ). In addition, the hazard of ADL disability decreased by $4 \%$ as exercise increases $(p=0.002)$. History of dyslipidemia ( $p=$ 0.018 ) and rheumatoid arthritis $(p=0.028)$ was risk factors for disability by 1.7 and 1.8 times, respectively, more than healthy people. The history of falls during the past year that could cause disability to subjects was 2.2 times more than the absence of falls $(p=0.014)$. Emergency visits $(p=0.049)$ and having homecare $(p=$ 0.008 ) in the past 3 months were more disabling by 1.9 and 4.5 times, respectively. The results of the logistic regression are represented in Table 5.

Table 5: Binary logistic regression for independent factors associated with ADL disability

\begin{tabular}{|c|c|c|c|c|}
\hline & \multirow[t]{2}{*}{ P-value } & \multirow[t]{2}{*}{$\operatorname{Exp}(B)$} & \multicolumn{2}{|l|}{$95 \% \mathrm{Cl}$} \\
\hline & & & Lower & Upper \\
\hline \multicolumn{5}{|l|}{ Smoking } \\
\hline Non-smoking & & - & & \\
\hline Smoking & 0.019 & 2.160 & 1.135 & 4.109 \\
\hline \multicolumn{5}{|l|}{ Exercise } \\
\hline No & & - & & \\
\hline Yes & 0.002 & 0.412 & 0.235 & 0.721 \\
\hline \multicolumn{5}{|l|}{ Dyslipidemia } \\
\hline No & & - & & \\
\hline Yes & 0.018 & 1.763 & 1.102 & 2.821 \\
\hline \multicolumn{5}{|c|}{ Rheumatoid arthritis } \\
\hline No & & - & & \\
\hline Yes & 0.028 & 1.841 & 1.067 & 3.177 \\
\hline \multicolumn{5}{|l|}{ History of fall } \\
\hline No & & - & & \\
\hline Yes & 0.014 & 2.223 & 1.172 & 4.216 \\
\hline \multicolumn{5}{|l|}{$\begin{array}{l}\text { Emergency visit } \\
\text { homecare }\end{array}$} \\
\hline No & & - & & \\
\hline Yes & 0.049 & 1.891 & 1.002 & 3.568 \\
\hline \multicolumn{5}{|l|}{ Homecare } \\
\hline No & & - & & \\
\hline Yes & 0.008 & 4.504 & 1.492 & 13.595 \\
\hline
\end{tabular}

\section{IADL disability}

The overall prevalence of IADL disability among the participants was $58.5 \%$. As shown in Table 3 , the moderate disability was $38.7 \%$ and the severe disability was $19.8 \%$. Furthermore, the most IADL functions were affected was transportation $(40.7 \%)$, followed by shopping $(24.6 \%)$, laundry $(19.6 \%)$, food preparation $(19 \%)$, housekeeping $(14.1 \%)$, responsibility for own medications (13.7), ability to handle finances $(8.7 \%)$, and ability to use the telephone (3.4\%).

Using the univariate analysis, as shown in Table 4, we found that the IADL disability was significantly $(P<.001)$ higher among subjects aged $\geq 68$ years than younger than 68 years, women than men, uneducated than educated, among non-workers, compare to others, unmarried than married, who was living with other than husband/wife with children, and who had a caregiver and especially a family member. The disability of IADL was more likely higher among inactive participants $(p<0.001)$, hypertensive patients $(p=0.010)$, history of cancer $(p=0.044)$, and history of emergency visits $(p=0.029)$, or homecare in the past 3 months $(p=0.003)$.

Further analysis showed that there were several predictor factors associated with IADL. Based on the data, statistically significant findings were reported between the occurrence of IADL and advanced age, gender, caregiver status, exercise routine, and independence. As shown in Table 6, participants older than 80 years of age were 3.9 times more likely to have IADL than younger subjects ( $p=0.004$ ), female participants were 1.8 times more likely than males $(p=0.029)$, those with a caregiver were 2.6 times more likely than those without a caregiver $(p=0.000)$, physically inactive participants were 3 times more likely than with those with exercise routines $(p=0.000)$, and participants that needed homecare were 9.6 times more likely than independent participants $(p=0.009)$.

Table 6: Binary logistic regression for independent factors associated with IADL disability

\begin{tabular}{|c|c|c|c|c|}
\hline & \multirow[t]{2}{*}{$\mathrm{P}$-value } & \multirow[t]{2}{*}{$\operatorname{Exp}(B)$} & \multicolumn{2}{|c|}{$95 \%$ confidence level } \\
\hline & & & Lower & Upper \\
\hline \multicolumn{5}{|l|}{ Age } \\
\hline$<80$ years & & - & & \\
\hline$\geq 80$ years & 0.004 & 3.974 & 1.544 & 10.230 \\
\hline \multicolumn{5}{|l|}{ Sex } \\
\hline Male & & - & & \\
\hline Female & 0.029 & 1.896 & 1.068 & 3.368 \\
\hline \multicolumn{5}{|c|}{ Having a caregiver } \\
\hline No & & - & & \\
\hline Yes & 0.000 & 2.565 & 1.595 & 4.124 \\
\hline \multicolumn{5}{|l|}{ Exercise } \\
\hline No & & - & & \\
\hline Yes & 0.000 & 0.329 & 0.199 & 0.547 \\
\hline \multicolumn{5}{|l|}{ Homecare } \\
\hline No & & - & & \\
\hline Yes & 0.009 & 9.575 & 1.747 & 52.487 \\
\hline
\end{tabular}

\section{Discussion}

Comorbidity, age-related frailty, and acute illness place older people at increased risk for adverse outcomes and are associated with more rapid declines in health status and a greater likelihood of disability [21].

In the current study, the prevalence of ADL disability among the participants was $24.6 \%$. This finding was higher than a study conducted in 1994 in the Qassim region which estimated ADL prevalence at $12.4 \%$ among older people registered in PHCCs [22]. One possible reason for these finding differences might because of the change in sedentary lifestyles among old people during the past few decades. However, the current study found a lower percentage of ADL disability among participants when compared to a study on older individuals in a major hospital in Jeddah. It is important to note that the different settings could play a role in the effect of comorbidity on the patients [23]. Regionally, in the United Arab Emirates, only $5.8 \%$ of older people patients who registered in the home-based primary care at Dubai Health Authority were independent [24]. The prevalence of ADL disability in this study was lower than the figure reported by a cross-sectional study. In Tunisia, that was carried out in long-stay long-term care institutions of older persons, as it was found to be $57.3 \%$ [5]. Internationally, in Spain, among nursing 
home residents, $79.8 \%$ were disabled based on the Barthel Index which was a scale designed to measure the performance of $10 \mathrm{ADL}$ functions [25]. The higher figures of ADL disability in Tunisia and Spain were due to different study settings and different tools used in Spain, as older people in long-term care facilities usually suffer from multi-morbidities and dependence. The prevalence of ADL disability in this study was higher than a study in Brazil, as the basic activity disability in the Northeast region was $8.4 \%$ resulted from the study which was driven by the National Health Survey [26]. This difference may be related to different study samples as in Brazil it was a national survey while this study targeted PHCCs attendants. In general, there were differences between our findings and other studies because of variation of population characteristics, cultures, and social life. The Saudi older people used to live in their families with their children and grandchildren, hence, the institutions of the older people were not quite common in Saudi Arabia.

Furthermore, this study showed that the prevalence of disability in IADL, either moderate or severe disability, was $58.5 \%$. This finding was compatible with the result of a previous study in Qassim, which found IADL impairment at a rate of $54.4 \%$ [22]. Previous scholarship has found high percentages of IADL as well. For example, this study's findings had a lower prevalence than that found among institutionalized Tunisian older people (85.4\%) [5]. However, the current study had a higher percentage of IADL than the findings from a study on Brazilian older people (34.2\%) [19]. Because IADL included higher-level tasks, its disability used to be higher than disability in ADL functions.

This study analyzed the factors associated with disability among Saudi older people. With regard to the sex and age of participants, data indicated that the ADL and IADL disabilities were higher among females and people more advanced in age. These findings are supported by similar findings in different geographical regions, including but not limited to, the Qassim region of Saudi Arabia [22], Tunisia [5], Spain [25], Brazil [26], and China [27].

We found that a need for homecare was positively associated with ADL and IADL disabilities. Homecare, defined as "the provision of medical supplies and/or clinical services directly to patients in the community," is generally offered as a pre-hospitalization preventive measure or a post-hospitalization procedure to enable elderly people to live independently as long as possible [28]. The previous study has also suggested that homecare is a risk factor for disability [19].

This study showed that ADL dependency was associated with the history of smoking either among current smokers or ex-smokers. This aligns with a study that found that smokers and ex-smokers in Belgium had a shorter life expectancy and more years lived with disability compared with non-smokers [29]. Furthermore, a large population-based health survey in Norway showed that smoking and physical inactivity were the most important lifestyle risk factors for needing assistance in ADL [30].

Based on data analysis, regular exercise was a protective factor against both ADL and IADL disabilities. Similar findings indicated that the low level of physical activity was a predisposing factor for developing a disability among individuals aged 60 years or older [23], [31]. This was supported by results of literature systematic reviews and metaanalyses that suggested the association between a sedentary life and physical disability in older adults [32]. It was difficult to made causality inferences in our study. Hence, there was a possibility that physical inactivity might be a result of functional disability. Another systematic review suggested that the older people who were more physically active or who did regular exercise had a lower risk of developing ADL disability [33].

This study found that the medical history of dyslipidemia and rheumatoid arthritis was associated with ADL disability. Dyslipidemia is a major risk factor for cardiovascular diseases, which can cause death and disability [34]. The difficulty in performing ADL among patients with rheumatoid arthritis is well known, and the hallmark feature is persistent symmetric polyarthritis [35]. Further, this study found that a history of falls during the past year was associated with disability in basic activity. The risk of fractures and injuries due to falling can restrict movement and increase dependency on others. This was compatible with a longitudinal study in the United States that concluded that a history of falling was a risk for future ADL dependency [36]. In addition, we found that emergency visits during the past 3 months were associated with increased ADL disability among the participants. Similar to a study conducted in Italy, we suggest that ADL disability increases the risk of emergency room visits but not of hospital admissions [37].

This study has limitations. First, it was difficult to make causal inferences due to the nature of the crosssectional studies. We used a non-probability sampling method for the difficulty in detecting the targeted total population because the primary health services are provided by many sectors other than the ministry of health. In addition, we focused solely on PHCCs, even though elderly citizens were scattered between primary, secondary, and tertiary health centers. Hence, we may be biased toward slightly independent elderly persons and missed a broad segment of the sub-population. Therefore, the possibility of selection bias should be considered. To the best of the authors' knowledge, this is the first study performed in the city of Riyadh, Saudi Arabia, examining functional disability among elderly citizens attending PHCCs. 


\section{Conclusion}

This study found a high prevalence of ADL and IADL disability among Saudi older people in Riyadh city. We concluded that smoking, dyslipidemia, and rheumatoid arthritis, history of falls, and emergency visits were risk factors associated with ADL disability. The predictors of IADL disability were advanced age, being female, and the need for a caregiver. Furthermore, the need for homecare was positively associated with ADL and IADL dependency, and maintaining regular physical activity was a protective factor against functional disabilities.

\section{Recommendations}

Scholars and health-care practitioners should focus on preventive measures that will allow the growing number of elderly people to be independent members of society. Primarily, they should focus on preventing the predisposing factors of chronic diseases and emphasizing healthy habits such as exercise among adults younger than 60 years. Second, additional measures and resources are needed for screening and treating elderly people that are in the early stages of diseases to control the future probability of disabilities incidences. It is important that greater efforts are made to prevent the sequences of disabilities and mitigate the complications that would be caused by chronic diseases.

\section{References}

1. Kaur G, Bansal R, Anand T, Kumar A, Singh J. Morbidity profile of noncommunicable diseases among elderly in a city in North India. Clin Epidemiol Glob Health. 2019;7(1):29-34. https://doi. org/10.1016/j.cegh.2017.12.004

2. United Nations DESA. World Population Prospects: The 2017 Revision, Key Findings and Advance Tables. New York: United Nations DESA; 2017.

3. Khoja AT, Aljawadi MH, Al-Shammari SA, Mohamed AG, Al-Manaa HA, Morlock L, et al. The health of Saudi older adults; results from the Saudi national survey for elderly health (SNSEH) 2006-2015. Saudi Pharm J. 2018;26(2):292-300. https://doi.org/10.1016/j.jsps.2017.11.008

PMid:30166931

4. World Development Indicators, Data Bank; 2020. Available from: https://www.databank.worldbank.org/source/worlddevelopment-indicators. [Last accessed on 2020 Jun 07].

5. Mellouli M. Prevalence and Associated Factors of Functional Disability in Activities of Daily Living and Instrumental Activities among Institutionalized Tunisian Elderly; 2020. Available from: https://www.researchgate.net/publication/319421016_ prevalence_and_associated_factors_of_functional_disability in_activities_of_daily_living_and_instrumental_activities_ among institutionalized tunisian elderly. [Last accessed on 2020 May 12]. https://doi.org/10.9734/air/2017/35889
6. World Health Organization. International Classification of Functioning, Disability and Health: ICF. Geneva: World Health Organization; 2001. Available from: https://apps.who.int/iris/ handle/10665/42407

7. Bindawas SM, Vennu V. The national and regional prevalence rates of disability, type, of disability and severity in Saudi Arabia-analysis of 2016 demographic survey data. Int J Environ Res Public Health. 2018;15(3):419. https://doi.org/10.3390/ ijerph15030419 PMid:29495546

8. Al-Jadid MS, Al-Jadid M. Disability in Saudi Arabia review articles. Saudi Med J. 2013;34(5):453-60. Available from: https://www.smj.org.sa. [Last accessed on 2020 May 05].

9. Ajmi T, Ghardallou M, Toumi J, Limam M, Mtiraoui A, Sahli J, et al. Prevalence and associated factors of functional disability in activities of daily living and instrumental activities among institutionalized tunisian elderly. Adv Res. 2017;11(3):1-10. https://doi.org/10.9734/air/2017/35889

10. Mitra S, Palmer M, Kim H, Mont D, Groce N. Extra costs of living with a disability: A review and agenda for research. Disabil Health J. 2017;10(4):475-84. https://doi.org/10.1016/j. dhjo.2017.04.007

PMid:28501322

11. Daniel WW. Biostatistics: A Foundation for Analysis in the Health Sciences. 7th ed. New York: Jhon Wiley and Sons; 1999. Available from: https://www.wiley.com/college/daniel. [Last accessed on 2020 May 07].

12. Available from: https://www.web.archive.org/ web/20140702070214; http://www.riyadh.gov.sa/en/pages/ riyadhcity.aspx. [Last accessed on 2020 May 10].

13. Nations U. The World's Cities in 2018. World's Cities 2018Data Booklet (ST/ESA/SERA/417); 2018. p. 34. https://doi. org/10.18356/c93f4dc6-en

14. Katz S, Akpom CA. A measure of primary sociobiological functions. Int J Health Serv. 2005;6(3):493-508. https://doi. org/10.2190/uurl-2ryu-wryd-ey3k PMid:133997

15. Brown RW. Assessment of older people: Self-maintaining and instrumental activities of daily living. J Am Med Assoc. 1949;139(7):474.

16. Palmer M, Harley D. Models and measurement in disability: An international review. Health Policy Plan. 2012;27(5):357-64. PMid:21729911

17. Azad A, Mohammadinezhad T, Taghizadeh G, Lajevardi L. Clinical assessment of activities of daily living in acute stroke: Validation of the Persian version of Katz Index. Med J Islam Repub Iran. 2017;31(1):178-83. https://doi.org/10.18869/ mjiri.31.30 PMid:29445659

18. Nasser R, Doumit J. Validity and reliability of the arabic version of activities of daily living (ADL). BMC Geriatr. 2009;9(1):11. https://doi.org/10.1186/1471-2318-9-11

PMid:19327172

19. Nunes JD, de Oliveira Saes M, Nunes BP, Siqueira FCV, Soares DC, Fassa ME, et al. Indicadores de incapacidade funcional e fatores associados em idosos: Estudo de base populacional em Bagé, Rio Grande do Sul. Epidemiol Serviços Saúde. 2017;26(2):295-304. Available from: http://www. revista.iec.gov.br/template_doi_ess.php?doi=10.5123/S167949742017000200295 and scielo=S2237-96222017000200295. [Last accessed on 2020 May 27]. https://doi.org/10.5123/ s1679-49742017000200007

20. Edwards MM. The reliability and validity of self-report activities of daily living scales. Can J Occup Ther. 1990;57(5):273-8. https://doi.org/10.1177/000841749005700507 
21. Ellis G, Gardner M, Tsiachristas A, Langhorne P, Burke O, Harwood $\mathrm{RH}$, et al. Comprehensive geriatric assessment for older adults admitted to hospital. Cochrane Database Syst Rev. 2017;9(9):CD006211. https://doi.org/10.1002/14651858. cd006211.pub3 PMid:28898390

22. Al-Mahadi MA, Elzubier AG. Assessment of the functional status of elderly subjects in Qassim Region, Saudi Arabia. J R Soc Health. 1997;117(5):313-8. https://doi. org/10.1177/146642409711700509 PMid:9519664

23. Al Senany S, Al Saif A. Assessment of physical health status and quality of life among Saudi older adults. J Phys Ther Sci. 2015;27(6):1691-5. https://doi.org/10.1589/jpts.27.1691 PMid:26180299

24. Alshaali A. Health Profile of Elderly Patients Registered in the Elderly Home Based Primary Care, Dubai, United Arab Emirates, Semantic Scholar; 2020. Available from: https://www. semanticscholar.org/paper/health-profile-of-elderly-patientsregistered-in-\%2c-alshaali-jaziri/46980f6557b1cd0bd2339b3cff 21e4ac1df34173. [Last accessed on 2020 May 12]. https://doi. org/10.5742/meaa.2015.92609

25. Serrano-Urrea R, Gómez-Rubio V, Palacios-Ceña $D$, Fernández-De-Las-Peñas C, García-Meseguer MJ. Individual and institutional factors associated with functional disability in nursing home residents: An observational study with multilevel analysis. PLoS One. 2017;12(8):e0183945. https://doi. org/10.1371/journal.pone. 0183945

PMid:28846744

26. de Oliveira-Figueiredo DS, Felisbino-Mendes MS, Malta DC, Velásquez-Meléndez JG. Prevalence of functional disability in the elderly: Analysis of the national health survey. Rev Rede Enferm Nord. 2017;18(4):468. Available from: https://www. researchgate.net/publication/319380991_prevalence_of functional_disability_in_the_elderly_analysis_of the national health_survey. [Last accessed on 2020 May 20 ]. https://doi. org/10.15253/2175-6783.2017000400007

27. Liang Y, Welmer AK, Möller J, Qu C. Trends in disability of instrumental activities of daily living among older Chinese adults, 1997-2006: Population based study. BMJ Open. 2017;7(8):e016996. https://doi.org/10.1136/ bmjopen-2017-016996

PMid:28851795

28. World Health Organization. The Growing Need for Home Health Care for the Elderly: Home Health Care for the Elderly as an Integral Part of Primary Health Care Services. Geneva: World Health Organization; 2015. p. 1-24. Available from: https://www.apps.who.int/iris/handle/10665/326801. [Last accessed on 2020 May 13]. https://doi.org/10.1300/ j027v07n01_03

29. van Oyen $H$, Berger N, Nusselder W, Charafeddine R, Jagger C, Cambois $\mathrm{E}$, et al. The effect of smoking on the duration of life with and without disability, Belgium 1997-2011. BMC Public Health. 2014;14(1):723. https://doi.org/10.1186/1471-2458-14-723 PMid:25026981

30. Storeng SH, Sund ER, Krokstad S. Factors associated with basic and instrumental activities of daily living in elderly participants of a population-based survey: The nord-trøndelag health study, Norway. BMJ Open. 2018;8(3):e018942. https:// doi.org/10.1136/bmjopen-2017-018942 PMid:29530908

31. Ahmad NA, Kasim NM, Mahmud NA, Yusof YM, Othman S, Chan YY, et al. Prevalence and determinants of disability among adults in Malaysia: Results from the national health and morbidity survey (NHMS) 2015. BMC Public Health. 2017;17(1):756. https://doi.org/10.1186/s12889-017-4793-7 PMid:28962562

32. deLima ScherLM, da GuardaFR, deBarros MV, ChenZ,AntonSD. Sedentary time and disability in older adults: A systematic review and meta-analysis. J Aging Sci. 2019;7(2):21-3. Available from: https://www.longdom.org/open-access/sedentarytime-and-disability-in-older-adults-a-systematic-review-andmetaanalysis-43921.html. [Last accessed on 2020 May 27]. https://doi.org/10.35248/2329-884.19.07.206

33. Vermeulen J, Neyens JC, van Rossum E, Spreeuwenberg MD, de Witte LP. Predicting ADL disability in communitydwelling elderly people using physical frailty indicators: A systematic review. BMC Geriatr. 2011;11(1):33. https://doi. org/10.1186/1471-2318-11-33 PMid:21722355

34. Michel JD. Oxford Textbook of Geriatric Medicine. Oxford: Oxford University Press; 2018. p. 1432. Available from: https:// www.books.google.com.sa/books?id=n u-dwaaqbaj and pg=pa737 and lpg=pa737 and dq=dyslipidemia+adl+disability and source=bl and ots=22gssbn4 4 h and sig=acfu3u25bd0 w8br2biiOr170l7sdxefshg and $\mathrm{hl}=\mathrm{ar}$ and $\mathrm{sa}=\mathrm{x}$ and ved=2ahukewiq8rpljq7pa hxtshuihrmecp0q 6aewa3oecao $q a q \# v=$ onepage and $q$ and $f=$ true. [Last accessed on 2020 May 12].

35. Rheumatoid Arthritis (RA) Clinical Presentation: History, Physical Examination, Stiffness, Tenderness, and Pain on Motion; 2020. Available from: https://www.emedicine.medscape.com/ article/331715-clinical\#b1. [Last accessed on 2020 May 12].

36. Sekaran NK, Choi H, Hayward RA, Langa KM. Fall-associated difficulty with activities of daily living in functionally independent individuals aged 65 to 69 in the United States: A cohort study. J Am Geriatr Soc. 2013;61(1):96-100. https://doi.org/10.1111/ jgs. 12071 PMid:23311555

37. Laudisio A, Marzetti E, Franceschi F, Bernabei R, Zuccalà G. Disability is associated with emergency room visits in the elderly: A population-based study. Aging Clin Exp Res. 2015;27(5):663-71. https://doi.org/10.1007/s40520-015-0324-5 PMid:25680781 